\title{
Self-Injectable Adrenaline for Anaphylactic Emergencies: Effectiveness of Epipen and Anapen - Are they Fit for Purpose - Evidence to Date
}

\section{Felix Simon Francis Ram*}

Massey University, School of Health Sciences, Auckland, New Zealand

Life-threatening anaphylactic emergencies are largely unpredictable. Adrenaline is widely accepted as first-line therapy for anaphylaxis, due to its physiological effects in reversing symptoms of anaphylaxis and with studies showing both reductions in morbidity and mortality associated with its administration [1-4]. Anaphylaxis can prove fatal, therefore learning how to use an adrenaline auto-injector is crucial for people with allergies and parents of children who have previously suffered from anaphylaxis. Such people must carry an adrenaline autoinjector with them at all times for administration when required. It is surprising that there are currently no internationally accepted criteria, including International Organization of Standards or other governmental regulatory requirements to benchmark the performance of adrenaline auto-injectors under standard conditions as there are for insulin pen injectors $[5,6]$.

World-wide and in New Zealand the two most commonly encountered single use adrenaline auto-injectors include the Epipen [7] which was approved by the New Zealand Regulatory Authority, Medsafe back in February 1997 and Anapen [8] which was approved for use by Medsafe in December 2009. It is often mistakenly assumed that these two auto-injectors are the same devices and that Anapen is a generic "equivalent" of the original Epipen auto-injector. Although both devices contain the same dose of adrenaline $(300 \mathrm{ug} / 0.3 \mathrm{ml}$ for adults or $150 \mathrm{ug} / 0.3 \mathrm{ml}$ for children) these are two very different devices. The Epipen employs a cartridge-based system (Figure 1) and was specifically designed for intramuscular self-administration of adrenaline. Anapen is a syringe-based device (Figure 2) which was originally designed for subcutaneous self-administration of insulin but has recently been employed for the administration of adrenaline; this fact is clearly evident in the design difference of these two autoinjectors.

A disadvantage with using a syringe delivery system is an extra operational step that requires the needle shield to be detached before removal of the safety cap, followed by thumb activation of the device by pushing a button [8]. This extra operational step may increase the risk of misuse because patients have to memorize and undertake
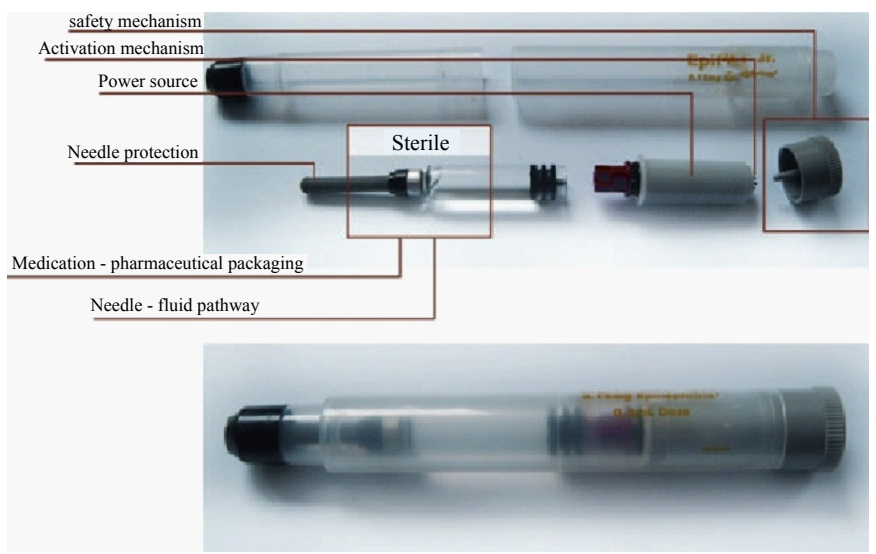

Figure 1: Epipen - cartridge-based device. the correct operational sequence at a time of medical urgency. After thumb activation, the released spring moves a prefilled syringe to its end position at which point the needle pierces through the tissue. The piston rod is then moved to its end position and the position of the end stop determines the volume of medication to be ejected. Therefore, with a syringe delivery system delivery of adrenaline starts as soon as pressure is applied to the piston rod which may result in deposition throughout the needle track resulting in loss of some or all medication before reaching the target muscle [9]. The effective penetration depth is a component of spring force applied, needle length, bore diameter and how easily the tissue is penetrated by the adrenaline solution. The glass syringe is a limiting factor in the design and limits the force that can be applied by the spring compared to cartridge-based systems. Epipen utilizes the cartridge-based system and when the safety cap has been removed, the injector is activated by holding the outer housing and pressing the device tip onto the tissue which permits the outer housing to move against the inner housing [7]. After activation, the released spring moves the cartridge and the attached needle to its end position, which then pierces through the rubber closure and into the tissue. Because of the high power of the remaining spring force, the sealing disc of the cartridge (closure) bursts and opens the fluid pathway [9]. Only then is the adrenaline released. The ejected volume is determined by the end stop on the attached piston rod. Therefore, in addition to having one less operational step in the cartridge-based Epipen device,
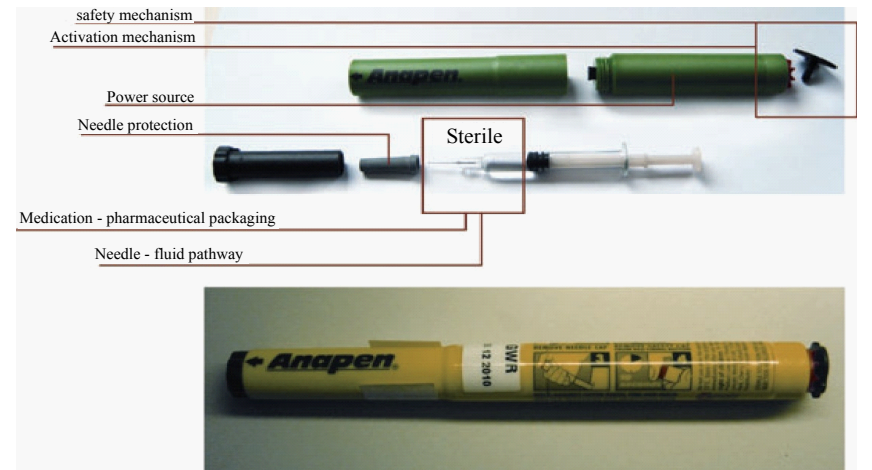

Figure 2: Anapen - prefilled syringe device.

*Corresponding author: Dr. Felix SF Ram, Senior Lecturer in Clinical Pharmacology, School of Health and Social Sciences, Massey University, Private Bag 102-904, North Shore, Auckland, New Zealand, Tel: +64 21 1077729; Fax: +64 9441 8165; E-mail: fsfram@yahoo.co.uk

Received February 09, 2012; Accepted March 28, 2012; Published March 31, 2012

Citation: Ram FSF (2011) Self-Injectable Adrenaline for Anaphylactic Emergencies: Effectiveness of Epipen and Anapen - Are they Fit for Purpose - Evidence to Date. J Aller Ther 3:116. doi:10.4172/2155-6121.1000116

Copyright: (c) 2011 Ram FSF. This is an open-access article distributed under the terms of the Creative Commons Attribution License, which permits unrestricted use, distribution, and reproduction in any medium, provided the original author and source are credited. 
adrenaline is only released once the needle is fully deployed into the tissue. This helps to ensure minimal loss of medication and delivery of adequate levels of adrenaline to the correct tissue compartment, that is, intramuscularly. An additional advantage of the cartridge-based device is the compression force generated during its operation. Adequate activation force during device operation compresses subcutaneous tissue, which results in the needle penetrating deeper within the tissue. Song et al. [10] in their ultrasound investigations into the role of compression has shown that an $8 \mathrm{lb}(3.6 \mathrm{~kg})$ activation force decreases the distance to muscle by $25 \%$ in women and $19 \%$ in men. Therefore, adrenaline can be delivered $25 \%$ and $19 \%$ deeper than the needle length alone in women and men, respectively, when using the cartridge-based Epipen auto-injector.

Figure 3 and 4 shows the needle length of both devices after activation for the adult and pediatric strengths. As the Anapen was originally designed for subcutaneous administration of insulin, it has an activated needle length of $7 \mathrm{~mm}$ for the adult strength or $8 \mathrm{~mm}$ for pediatric

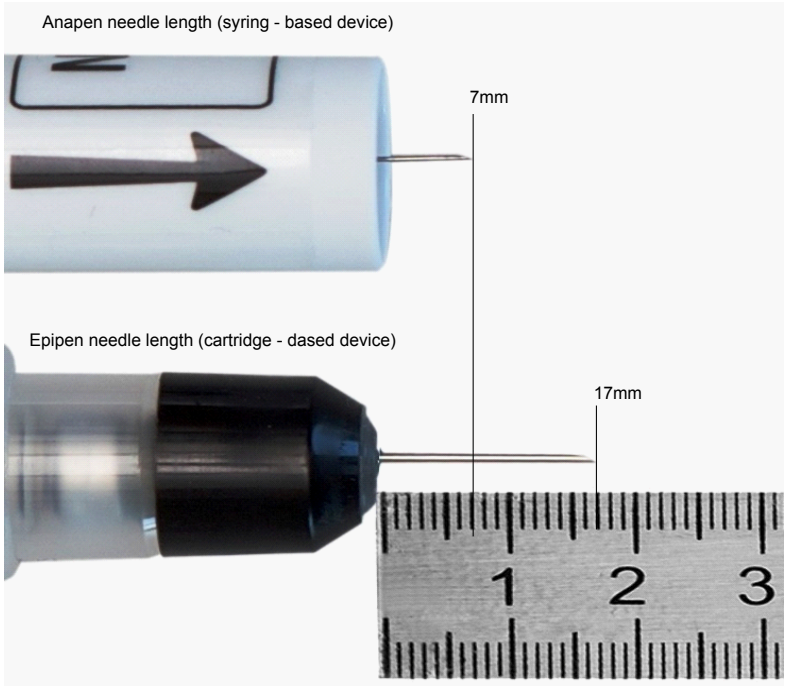

Figure 3: Adult adrenaline auto-injector needle length upon device activation

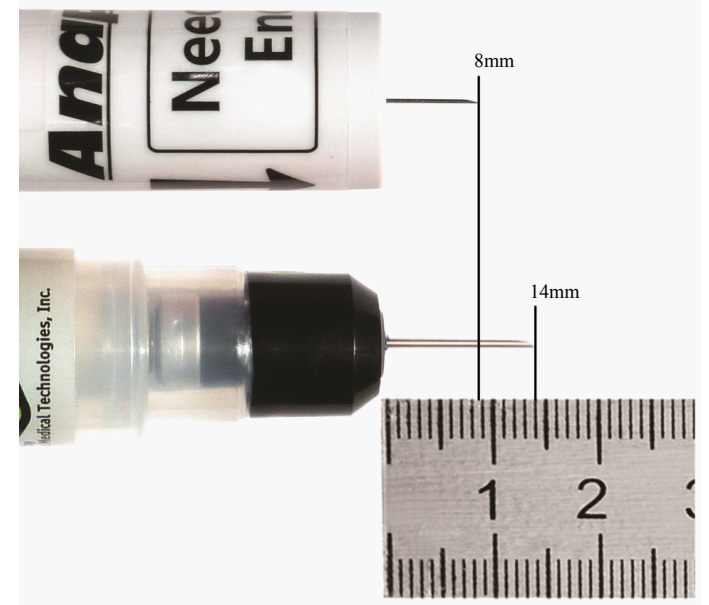

Figure 4: Pediatric adrenaline auto-injector needle length upon device activation strength. This ensures that insulin is injected into the subcutaneous layer and not into the muscle layer. Studies have demonstrated that the needle length must not exceed $8 \mathrm{~mm}$ in order to avoid administration of insulin into the muscle layer [11]. However, it is widely accepted that in an emergency adrenaline must be administered intramuscularly. This is because significantly faster peak plasma concentrations are reached when adrenaline is administered via the intramuscular route $(8 \pm 2$ min, mean \pm SEM) compared to the subcutaneous route (34 $\pm 14 \mathrm{~min}$ ) [12,13]. Epipen, when activated has a needle length of 17 $\mathrm{mm}$ for the adult strength (and $14 \mathrm{~mm}$ for the pediatric strength); this ensures that adrenaline is injected into the muscle layer and not into the subcutaneous layer. Studies have shown that the average distance (mean $\pm \mathrm{SD}$ ) from skin to muscle in the anterolateral aspect of the thigh is $6.6 \pm 4.7 \mathrm{~mm}$ in men, $14.8 \pm 7.2 \mathrm{~mm}$ in women [10] and ranges from $8.6 \pm 3.0 \mathrm{~mm}$ to $10.2 \pm 2.1 \mathrm{~mm}$ in children [14]. Therefore, the Anapen auto-injector needle is of inadequate length (being 7 or $8 \mathrm{~mm}$, Figures 3 and 4) to deliver adrenaline into the correct tissue compartment in an emergency. Furthermore, smaller needle length will also provide a smaller needle bore diameter (compared to the cartridge-based Epipen device) thus decreasing the rate and volume at which adrenaline will be administered into any tissue compartment.

During an anaphylactic emergency, not only it is important that adrenaline is administered into the correct tissue compartment $[15,16]$ but also that the correct dose of adrenaline is administered to achieve the desired clinical benefit.

A study conducted by Schwirtz and Seeger [17] has showed that upon device activation, Anapen only delivers $25.7 \%(0.08 \mathrm{ml}$ of the $0.3 \mathrm{ml}$ ) of the volume contained in this syringe-based delivery device, whereas the Epipen delivered $74.3 \%(0.22 \mathrm{ml}$ of the $0.3 \mathrm{ml})$ of the volume contained in this cartridge-based delivery device. Therefore, Anapen on average can only deliver 77 ug (or $25.7 \%$ ) of the possible $300 \mathrm{ug}$ of adrenaline per use, while Epipen delivers $223 \mathrm{ug}$ (or $74.3 \%$ ) of the possible $300 \mathrm{ug}$ of adrenaline per use. This is due to key differences between the two auto-injectors being: syringe-based vs. cartridgebased; $7 \mathrm{~mm}$ or $8 \mathrm{~mm}$ activated needle length vs. $17 \mathrm{~mm}$ or $14 \mathrm{~mm}$ activated needle length; differences in bore diameter, compression force upon activation and correct tissue compartment (subcutaneous vs. intramuscular) delivery of adrenaline.

For patients experiencing an anaphylactic emergency it is vital that a sufficient amount of the life saving drug, adrenaline, is promptly delivered to the correct tissue compartment in minimal time to ensure maximal clinical benefit. Given the evidence to date the cartridge-based adrenaline auto-injector device (Epipen) should be the only device recommended to patients for use in anaphylactic emergencies. This is because the Epipen adrenaline auto-injector device delivers a clinically adequate dose of adrenaline to the correct tissue compartment rapidly. Further research is needed to evaluate the quality and efficacy of these devices prior to approval. There is also an urgent need for governmental regulatory authorities throughout the world to provide guidelines on the manufacture and testing of these devices prior to grant marketing authorization.

\section{References}

1. Bock SA, Muñoz-Furlong A, Sampson HA (2001) Fatalities due to anaphylactic reactions to foods. J Allergy Clin Immunol 107: 191-193.

2. Gold MS, Sainsbury R (2000) First aid anaphylaxis management in children who were prescribed an epinephrine autoinjector device (EpiPen). J Allergy Clin Immunol 106: 171-176.

3. Kemp SF, Lockey RF, Wolf BL, Lieberman P (1995) Anaphylaxis. A review of 266 cases. Arch Intern Med 155: 1749-1754. 
Citation: Ram FSF (2011) Self-Injectable Adrenaline for Anaphylactic Emergencies: Effectiveness of Epipen and Anapen - Are they Fit for Purpose Evidence to Date. J Aller Ther 3:116. doi:10.4172/2155-6121.1000116

4. Sampson HA, Mendelson L, Rosen JP (1992) Fatal and near-fatal anaphylactic reactions to food in children and adolescents. N Engl J Med 327: 380-384.

5. European Medicines Agency (2006) Evaluation of Medicines for Human Use. Committee for Medicinal Products for Human Use. Annex guideline on similar biological medicinal products containing biotechnology-derived proteins as active substance: non-clinical and clinical issues. Guidance on similar medicinal products containing recombinant human insulin. London.

6. European Medicines Agency (2006) Pre-authorisation Evaluation of Medicines for Human Use. Committee for Medicinal Products for Human Use. Guideline on similar biological medicinal products containing biotechnology-derived proteins as active substance: non-clinical and clinical issues. London.

7. (2011) Medsafe, Ministry of Health. Epipen Medicines Datasheet/Product Details.

8. (2011) Medsafe, Ministry of Health. Anapen Medicines Datasheet/Product Details.

9. Frew AJ (2011) What are the 'ideal' features of an adrenaline (epinephrine) auto-injector in the treatment of anaphylaxis? Allergy 66: 15-24.

10. Song TT, Nelson MR, Chang JH, Engler RJ, Chowdhury BA (2005) Adequacy of the epinephrine autoinjector needle length in delivering epinephrine to the intramuscular tissues. Ann Allergy Asthma Immunol 94: 539-542.
11. Gibney MA, Arce CH, Byron KJ, Hirsch LJ (2010) Skin and subcutaneous adipose layer thickness in adults with diabetes at sites used for insulin injections: implications for needle length recommendations. Curr Med Res Opin 26: $1519-1530$

12. Simons FE, Gu X, Simons KJ (2001) Epinephrine absorption in adults: intramuscular versus subcutaneous injection. J Allergy Clin Immunol 108: 871 873.

13. Simons FE, Roberts JR, Gu X, Simons KJ (1998) Epinephrine absorption in children with a history of anaphylaxis. J Allergy Clin Immunol 101: 33-37.

14. Cook IF, Murtagh J (2002) Needle length required for intramuscular vaccination of infants and toddlers. An ultrasonographic study. Aust Fam Physician 31: 295297

15. Ellis AK, Day JH (2003) The role of epinephrine in the treatment of anaphylaxis. Curr Allergy Asthma Rep 3: 11-14.

16. Stecher D, Bulloch B, Sales J, Schaefer C, Keahey L (2009) Epinephrine autoinjectors: is needle length adequate for delivery of epinephrine intramuscularly? Pediatrics 124: 65-70.

17. Schwirtz A, Seeger H (2010) Are adrenaline autoinjectors fit for purpose? A pilot study of the mechanical and injection performance characteristics of a cartridge-versus a syringe-based autoinjector. J Asthma Allergy 3: 159-167. 